\title{
L. L. SZKUTNIK
}

\section{Perceptive and Expressive Skills in Language Learning}

The present article deals with certain practical problems of teaching adults.

In the natural use of language two aspects can be distinguished: perception and expression. Perception in this sense means the reception of language signals with understanding. When reception disturbances (e.g. non-language noises, indistinct writing etc.) are excluded, satisfactory perception depends upon the ability to listen and read with understanding. Listening and reading with understanding are perceptive skills. Expression, in the sense used here, means the ability to transmit information consciously and effectively by means of speech and writing. Effective speaking and writing are expressive skills.

Drawing a distinction between perceptive and expressive skills seems to be of practical value to the language teacher, particularly when the following facts are considered:

1. For various and complex reasons most language courses for adults are quick courses with a limited number of lesson periods. This inevitable situation has to be accepted as the basis for any realistic discussion about methods of language teaching.

2. Language cannot be taught quickly in its extensive, natural form. Certain parts of it must be excluded. It is necessary to decide what can be excluded without disrupting the process of communication.

3. It is possible for the learner to express a great deal in a very simple way (provided that he is taught properly), but it is unrealistic to expect that the average native speaker (or writer) will be able and willing to make his ways of expression identical with those of the learner. It follows that the learner's ability to understand should cover a much wider area of language than his ability to express himself does. The relationship between the perception and expression areas can be represented graphically (p. 126).

The smaller circle represents the expression area which constitutes the kernel of the perception area - represented by the larger circle. (The central position of the expression area is acknowledged when speech is given priority in language teaching). 
4. Practice shows that perceptive and expressive skills can be acquired independently of each other (though they naturally influence each other). This can easily be illustrated by examples.

A considerable number of people in Po-

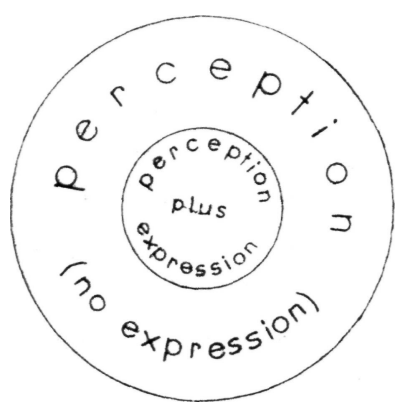
land have taught themselves to read English. (This is particularly frequent among scientific workers, doctors, engineers and economists who are interested in English publications). As a rule those self-taught adults can neither understand spoken English nor express themselves in English. They often make much worse learners of spoken English than complete beginners do.

On the other hand, adult students after working through a short but well organized course with a professional teacher can acquire considerable proficiency in the expressive skills (mainly speech). At the same time they have great difficulties in understanding a native speaker talking naturally or a native writer writing naturally. However, they make very good learners of the perceptive skills.

Among Poles who came to live in Britain (years ago) as adults and who have never studied English with a professional teacher, the ability to understand the spoken language is quite considerable. The ability to read varies. The ability to express themselves is very limited. It seems to have sprung spontaneously from the perceptive skills.

It follows that the expressive skills can be successfully (and quickly) taught only with the assistance of a properly-trained teacher (preferably well-equipped technically) whereas the perceptive skills can be acquired without (or with very little of) such assistance. Lessons (few as they are) should therefore be devoted to developing the expressive skills. The perceptive skills can be acquired by listening to specially prepared recordings and by reading specially prepared texts. Both listening and reading should take place outside the classroom. It may be not out of place to point out here that no one-man language laboratory booths are necessary in order to develop listening skills. An ordinary tape-recorder or even a record-player can do the job for quite a number of people.

To conclude it might be relevant to point out that particular native speakers themselves are able to understand much more than they can express. Therefore teaching the perceptive skills on a much wider scale than the expressive skills seems to be not only justified by practical requirements, but also perfectly natural. 